\title{
O DISCURSO MIDIÁTICO E AS REPRESENTAÇÕES SOCIAIS DO ESPORTE: O ATLETA COMO MODELO DE COMPORTAMENTO
}

\author{
Doiara Silva dos Santos \\ Universidade Federal do Espírito Santo, Vitória, Espírito Santo, Brasil
}

Ana Gabriela Alves Medeiros

Universidade Estadual de Santa Cruz, Ilhéus, Bahia, Brasil

\begin{abstract}
Resumo
A mídia tem transformado os processos de comunicação e suscitado novas interações comunicativas entre os atores sociais. Tais processos geram códigos específicos que produzem efeitos de percepção, recepção e comportamentos sociais. Este estudo buscou identificar de que forma o atleta se constitui como ator social do esporte no discurso midiático. Foram analisadas reportagens da Revista Veja - de circulação nacional e grande visibilidade na mídia impressa brasileira -, presentes na seção de esportes de janeiro de 2007 a janeiro de 2008 . Verificou-se a figura mítica do atleta como ator social do esporte, bem como suas representações como modelo de comportamento.

Palavras-chave: Mídia impressa - Atleta - Análise de Conteúdo.
\end{abstract}

\section{Introdução}

$\mathrm{O}$ s jornais, rádio, revistas, cinema e televisão constituem marcos históricos e sociais na história das mídias. Desde seu advento, em que o público receptor das mensagens era tido como homogêneo - e isso configurou o que foi denominado comunicação de massa -, até as novas tecnologias na sociedade contemporânea, os processos comunicativos das mídias geram códigos (BRIGGS; BURKE, 2004).

Esses códigos são específicos e produzem efeitos de percepção, processos de recepção e comportamentos sociais. A mídia tem transformado os processos de comunicação e suscitado novas interações comunicativas entre os atores sociais. Diante disso, o presente estudo buscou identificar de que forma o atleta se constitui como ator social do esporte no discurso midiático.

Para tanto, foram analisadas reportagens da Revista Veja - de circulação nacional e grande visibilidade na mídia impressa brasileira - presentes na seção de esportes de janeiro de 2007 a janeiro de 2008 que incluem a expectativa e realização dos Jogos Pan-americanos do Rio em 2007 e o período que antecede os Jogos Olímpicos de Pequim em 2008.

Diante desse objetivo, perspectivamos a cultura esportiva como parte da cultura contemporânea; definida como "[...] um conjunto de ações, valores e compreensões que representam o modo predominante de ser/estar na sociedade globalizada, em relação ao seu âmbito esportivo", tem significações simbólicas que vêm sendo incor- 
poradas - dada a força do apelo midiático e seu efeito multiplicador - pela sociedade (PIRES, 2001, p. 15).

Diante disso, a cultura como um todo e o fenômeno esportivo tendem a um processo de mundialização crescente e não mais abdicam da participação da mídia na sua produção, difusão ou transformação (THOMPSON, 1995). Deste modo, o esporte e a mídia estão compreendidos numa relação de reciprocidade.

Nesse sentido, a mídia constitui-se como uma indústria que produz e veicula símbolos e significados que têm implícito um conjunto de elementos, os quais interferem na estruturação, organização e reorganização do que se percebe na realidade em que o receptor está inserido. A discussão do esporte mediante este processo de espetacularização, seus significados e símbolos quanto às possibilidades de intervenção em educação devem suscitar questionamentos que envolvam a diferenciação entre passividade e atividade, entendendo o consumo inconsciente como um fator alienante do potencial criador e da imaginação (KELLNER, 2006).

De fato, o discurso midiático influencia a informação e/ou o conhecimento que se tem a respeito de um fato, os padrões de linguística, as ações sociais, as atitudes e as emoções. Nesse sentido, deixa de ser meramente instrumental para ser estrutural. A comunicação muda o lugar da cultura na sociedade tornando-se estruturante e reestruturante.

Assim, a globalização econômica e informacional contribui para a descentralização de saberes que podem e devem ser mediados, compreendidos e discutidos evitando o seu consumo pueril. Fischer (2002, p. 89) sugere que a análise dos discursos da mídia nas pesquisas educacionais precisa

[...] dar conta exatamente da complexa trama existente entre a linguagem específica em correlação com os sentidos que nela circulam e são construídos, elementos que não se separam do modo de ser e estar, no interior das práticas de produção, veiculação e recepção de produtos midiáticos.

Nesse viés, compreendemos o esporte como um fenômeno moderno, que não apenas teve influências do contexto da Revolução Industrial (sobretudo do modelo inglês), mas traz consigo os valores arraigados que tornam o atleta, por exemplo, um modelo de comportamento, uma figura mítica, um herói.

Para proceder a análise, foram selecionadas as reportagens/entrevistas às quais tinham como foco aspectos relacionados a um atleta ou um grupo de atletas. Foram excluídas aquelas que, embora tratassem de esporte, tinham como temática central, por exemplo, a saúde, a organização esportiva, etc.

Dessa forma, de janeiro de 2007 a janeiro de 2008, foram encontradas 26 reportagens na seção de esportes da Revista Veja. Destas, 13 compuseram o corpus desta análise por tratarem da temática específica à qual este estudo se propôs investigar (duas encontravam-se em seção especial específica dos Jogos Pan-americanos do Rio/2007 que substituiu a seção de esportes durante o evento mencionado).

A Análise de Conteúdo (AC) foi a técnica utilizada que permitiu a descrição das mensagens identificadas nas reportagens e/ou entrevistas. Por meio de procedimentos sistemáticos e objetivos, foram produzidas inferências de conteúdos relativos às condições de produção/recepção destas mensagens (variáveis inferidas) de acordo com o referencial teórico a partir dos quais chegamos à problematização deste estudo. 
Uma ficha de observação (FO) foi elaborada para a sistematização das análises das reportagens e/ou entrevistas presentes na seção de esportes. Esta continha, a saber: o título e suas respectivas informações relevantes; autoria e/ou entrevista; descrição de fotos/ilustrações; e o registro da data, edição e páginas. Vale destacar que esta documentação na $\mathrm{FO}$ facilita a identificação das reportagens uma vez que elas são de acesso público em edições impressas e, mais recentemente, seu conteúdo encontra-se em acervo digital (de acesso gratuito) no site da Revista Veja.

A FO utilizada neste estudo resultou de seu uso e aperfeiçoamento prévios, em uma reportagem da mesma revista, que contemplou a temática do estudo, mas, em outro período. Para o preenchimento da FO, no item informações relevantes, descrevemos cada reportagem bem como reproduzimos fragmentos que pudessem, ao mesmo tempo, facilitar o trabalho de análise e garantir o uso fidedigno de frases e termos.

Identificamos e destacamos para esta análise as seguintes categorias: (1) o atleta como símbolo identitário nacional; (2) o atleta "herói”; (3) o atleta vilão/transgressor. Entendemos que a primeira categoria tem influência direta sobre as demais, isso poderá ser verificado ao longo do texto.

É importante lembrar que a AC pode ser quantitativa e qualitativa. Existe uma diferença entre essas duas abordagens: a quantitativa busca estabelecer uma frequência das palavras que se repetem no conteúdo do texto (de acordo com objetivo da pesquisa); a qualitativa considera a presença ou a ausência de uma dada característica de conteúdo ou conjunto de características num determinado fragmento de mensagem e atenta, portanto, ao seu componente retórico (MINAYO; NETO; DESLANDES, 2003). Este estudo se delineia a partir da abordagem qualitativa da AC.

\section{O atleta, o herói, o vilão}

Percebeu-se que a figura do atleta nas reportagens analisadas esteve associada a alguns elementos comuns que interagem entre si, de acordo com as categorias verificadas. São elas: o herói, o vilão e, num contexto mais amplo, um modelo de comportamento vinculado a fatores identitários.

Em "Jovem de Grande Valor: Em apenas um ano Breno passou de Júnior a craque do São Paulo, e agora, vai para o Bayern de Munique" (2007a) percebe-se que a conquista de aspirações financeiras está vinculada à figura mítica do atleta, que não sucumbe às dificuldades diversas em sua trajetória e heroicamente as vence, depois de uma longa espera. Longa se considerarmos que muitos destes atletas chegam ainda meninos às divisões de base dos clubes.

A reportagem destaca a velocidade com que o jogador de futebol Breno viveu da aspiração de jogar num grande clube, se tornar ídolo e ganhar muito dinheiro à realização destes desejos. Uma ascensão "meteórica" que se deve a seu futebol "maduro e desembaraçado". Em um ano tornar-se ídolo, jogar num grande clube e ganhar muito dinheiro o identifica como um herói. É a idealização de sucesso presente neste discurso.

Esse processo é recorrente na revista em questão. A superação de situações adversas - que constata, nestes discursos, o caráter heróico atribuído ao atleta - perpassam desde questões socioeconômicas até as características físicas, o âmbito familiar 
conturbado, problemas de saúde, etc. É neste aspecto que identificamos a significação simbólica no contexto esportivo mediada pela mídia. Pires (2001, p. 16) ressalta que esta significação simbólica se refere "aos sentidos simbólicos que são atribuídos aos signos sociais representados pelas condutas e comportamentos dos integrantes de diversos segmentos do esporte".

A reportagem sobre a tenista belga Justine Henin, por exemplo, centra-se nas suas vitórias, "apesar da baixa estatura" e história atribulada (a mãe faleceu quando tinha 12 anos, aos 17 rompeu com o pai e foi morar com o namorado). O motivo do seu conflito com o pai (intenção de controlar sua carreira) é mencionado como um acontecimento muito frequente no mundo do tênis feminino (SALVADOR, 2007c).

A narrativa então detalha as dificuldades da atleta no que se refere à sua saúde. A descoberta de que a atleta sofria de asma crônica (motivo que a afastaria dos Jogos Olímpicos de Pequim) é relatada como mais um fator que pudesse fazê-la desistir. Esses fatores somados atribuem um sentido simbólico de realçar as vitórias da atleta, creditando a ela uma personalidade forte e combativa.

Já a "fama de bom moço" do jogador de futebol Kaká está diretamente associada ao seu sucesso no futebol italiano, sobretudo, à conquista de títulos (SALVADOR, 2007b). Segundo o texto, o jogador almeja ser símbolo da seleção brasileira e não teme as exigências de "pós-título" que comumente recai sobre os jogadores. Pode-se perceber que seu modelo de comportamento é ressaltado (como o fato de ele mesmo gerenciar seu dinheiro e investimentos). Por fim, ao ser questionado por que seu nome não aparece nos tablóides de fofoca, o "bom moço" respondeu: "simplesmente porque gosto de sair com a minha esposa ou meus amigos para jantar e sempre volto para casa cedo" (SALVADOR, 2007b, p. 128).

A figura "exemplar" do atleta é facilmente identificada, como também o é a associação de que seu sucesso profissional está vinculado a este fator. As significações simbólicas que percebemos neste discurso não restringem o "modelo" de comportamento do atleta ao seu desempenho profissional. Verificamos uma mediação destas significações que adentram também as relações sociais, familiares, etc.

Porém, o atleta também está na iminência de tornar-se "vilão". A reportagem sobre o jogador de futebol Richarlyson tem início com uma citação do que seria uma declaração do atleta na qual ele negou ser homossexual. Esta declaração foi uma resposta a boatos que surgiram após a comemoração de um gol em que ele realizou uma dança. De acordo com a declaração do jogador, tais boatos poderiam prejudicar sua carreira.

As declarações do juiz, que arquivou uma queixa-crime feita pelo jogador contra o dirigente administrativo do clube Palmeiras (cujas declarações fizeram parte destes boatos), são consideradas desastrosas e preconceituosas. As denominadas "pérolas" do juiz em questão, foram ilustradas como no fragmento a seguir: "a aceitação de homossexuais no futebol brasileiro prejudicaria a uniformidade do pensamento de equipe, o entrosamento, o equilíbrio, o ideal e até o torcedor que vai ao estádio com seu filho avistar seu time de coração" (BRASIL, 2007, p.100).

Percebe-se a "preocupação" do juiz em relação ao atleta como modelo de comportamento para quem assiste a seu desempenho esportivo - que passa a ser uma questão periférica - e, portanto, enxerga influências de seu comportamento sobre a 
família, o pensamento de equipe, o entrosamento e até a paixão do torcedor pelo time de coração.

No que concerne ao futebol, destacamos que essa narrativa permite interpretações que parecem convergir com o que Helal, Soares e Lovisolo (2001, p. 66) averiguaram sobre o forte apelo deste esporte no que se refere à construção da identidade nacional brasileira. Destacamos que estão em jogo valores, hábitos e um discurso moral em torno do esporte, neste caso em torno da homossexualidade.

Identificamos que este teor moralizante, sobretudo considerando a popularidade do futebol no Brasil, é recorrente dado o fato de que a preocupação do próprio atleta é notável. Ele, portanto, percebe e/ou incorpora o "seu papel" como modelo que é e influência que tem, teme a perda de um prestígio em relação ao público com quem cria uma identidade (afora as questões de "amor à camisa").

O fator identitário muito nos chama atenção para a narrativa sobre o jogador Richarlyson. As colaborações de Pires (2001, p. 16) nos fazem identificar o quão influente o discurso midiático pode ser no sentido de "ajudar a tornar familiares" e até determinar "papéis" para cada um dos segmentos e/ou atores do cenário esportivo. Mais que isso: estes discursos potencializam uma verdadeira "incorporação" destes papéis na cultura esportiva em si.

A reportagem sobre a atleta de golfe Angela Park caracteriza-se também pela relação entre esporte e identidade nacional. Trata-se do vislumbre de expandir a identidade esportiva a esportes pouco populares no Brasil sob o amparo do nacionalismo. Destaca-se o crescimento do golfe no país quanto ao número de praticantes e campos de golfe, apontando como fator decisivo para a popularização do esporte - e ainda ausente -, um ídolo nacional (TEIXEIRA, 2007).

Menciona-se a tentativa de divulgação do golfe por meio de ídolos de outros esportes como: Ronaldo Fenômeno (jogador de futebol) e Rubens Barrichelo (Fórmula 1). Uma estreante na liga profissional de golfe dos Estados Unidos, a brasileira Angela Park, se destacou e alcançou grandes resultados na liga do US Women's Open (torneio mais importante do mundo).

A atleta foi apelidada como golden girl (garota de ouro) pela imprensa americana. O presidente da Confederação Brasileira de Golfe, Álvaro Almeida, teria dito: "Para ser perfeito só faltava Angela ter um sobrenome bem brasileiro, como Silva [...] seria uma justificativa a mais para chamar a golfista de nossa" (SALVADOR, 2007c, p.126).

O mesmo aspecto - o nacionalismo - é identificado em "Phelps brasileiro: Recorde mundial faz de Thiago Pereira a grande promessa da natação para Pequim" (BORTOLOTI, 2007a). Desde o título - cuja referência heróica, campeã, se faz pela menção a um atleta de destaque no cenário internacional - até a "esperança" de medalhas confiada a Thiago Pereira, percebe-se a inter-relação entre a figura heróica e a representatividade nacional.

De fato, de acordo com Rubio (2002, p. 3), "a espetacularização do esporte moderno e supervalorização dos feitos e resultados alcançados pelo atleta têm sugerido uma relação entre o protagonista do espetáculo esportivo e a figura espetacular do herói”.

As narrativas da revista em questão transitam também entre a tecnologia e a figura mítica que consolidam o atleta como herói. Em "Próximo do limite: mesmo sem 
as principais estrelas, o Pan do Brasil reunirá máquinas humanas em busca de novos recordes" (2007) isso é notório. A partir das especificidades do treinamento de atletas como Jadel Gregório (salto triplo) e Thiago Pereira (natação), ressalta-se que, apesar de não se equiparar ao nível olímpico, o Pan-americano também traz consigo a capacidade de superação de seus atletas: "É na capacidade de chegar onde nenhum outro humano jamais chegou que reside o esporte de alto nível" (SOARES, 2007, p.75).

Pontua-se que a quebra de um recorde envolve fatores genéticos, tecnológicos, psicológicos, etc: "A competição olímpica é um grande laboratório dos limites do corpo humano" (SOARES, 2007, p.75). O Pan é apontado como a oportunidade de jovens talentos se consagrarem no cenário de competições internacionais; "No universo dos superatletas, o tempo tem um significado diferente do que representa para o resto da humanidade" (SOARES, 2007, p. 76).

Esse discurso permeia o desempenho atlético e o aporte tecnológico reforçando a condição mítica dos atletas por terem representações de tempo e espaço diferentes do "resto da humanidade". Denota a ideia de que a construção do mito contribui para uma compreensão da realidade cujas raízes não podem ser encontradas exclusivamente em explicações racionais. De fato, há um contexto propício e um jogo de interesses para perpetuar a paixão esportiva, esta relação recíproca entre mídia e esporte já foi mencionada anteriormente segundo as proposições de Thompson (1995).

De forma convergente, Rubio (2002) sugere que a tentativa de perpetuar a paixão esportiva culmina na "fabricação" dos ídolos esportivos. A mídia especializada faz uso dessa "fabricação" como uma pedra fundamental, na qual se assentam seus objetivos, e faz valer a máxima: não há esporte (de rendimento) sem ídolos.

O discurso da Revista Veja, porém, põe em foco que o Brasil não é uma potência esportiva e que os "nossos heróis" não são de todo "heróis", indo de encontro a essa máxima. No entanto, seria um equívoco desconsiderar que esse discurso se dá em tom de lamento. Em "Contra Hermanos e juvenis é fácil: O Brasil nunca teve tantos ouros. Mas, poucos atletas podem repetir o feito nas Olimpíadas"(2007), evidenciam-se as limitações dos "nossos combatentes" no esporte de alto nível.

Ressalta-se a melhor participação brasileira numa edição dos jogos Pan-americanos alertando: "Para um desavisado até podia parecer que o país é uma potência esportiva" [...], entretanto, "[...] os rotos e esfarrapados latino-americanos competiram com as equipes juvenis dos Estados Unidos e Canadá” (BORTOLOTI, 2007b, p. 88). Assim, não há motivo para euforia e expectativa quanto às chances nos Jogos Olímpicos de Pequim.

Os avanços são reconhecidos apesar de "estarmos longe do pelotão de frente Olímpico” (BORTOLOTI, 2007b, p. 89). Orçamentos das confederações de atletismo, ginástica e natação são citados como bons índices de evolução. Constatamos que o texto aponta para uma possível direção: "Só com dinheiro e planejamento o Brasil deixará a companhia dos rotos e esfarrapados que têm sua única festa de verdade nos Jogos Pan-americanos" (BORTOLOTI, 2007b, p. 89).

Com os heróis não tão heróis assim, emerge a discussão sobre a "perda" de alguns destes ídolos. A expansiva exportação de jogadores de futebol torna-se um tema recorrente na Revista. Para tal expansão dois fatores são apontados: a velocidade com que o Leste Europeu e a Ásia passaram a incorporar jogadores brasileiros em seu 
elenco; e o fato de que os clubes brasileiros não esperam o jogador ganhar fama e experiência, vendendo-os a preços não tão altos quanto poderiam.

O jogador Pepe não é mencionado como um exemplo deste contexto (FAVARO, 2007). Ele foi vendido aos 18 anos pelo Corinthians alagoano por 40 mil dólares ao Marítimo, seis anos mais tarde foi vendido ao Real Madrid por 30 milhões de euros. Helal, Soares e Lovisolo (2001) constatam e reforçam a forte identificação brasileira com o futebol. Entendemos que o sentimento de "perda" que identificamos neste discurso denota um saudosismo dessa forte identificação nacional com o futebol, paradoxalmente, personificadas e mitificadas na figura do ídolo/herói.

Não obstante, há os que deixam de ser heróis ainda que momentaneamente. Tendo sido, perdem esse status por algum motivo "transgressor" ao forte discurso ideológico em torno da moral no qual o esporte moderno está envolto. O doping é um desses motivos, como percebido em "Fraude na piscina: exame antidoping flagra Rebeca Gusmão, vencedora de duas medalhas de ouro no Pan” (2007).

O doping da nadadora Rebeca Gusmão, nos Jogos Pan-Americanos do Rio de Janeiro, fez com que "o Brasil" perdesse as primeiras medalhas de ouro da natação feminina, segundo o texto. No dia da abertura dos Jogos, a nadadora se submeteu a um exame antidoping no qual foi identificado alto índice de testosterona.Além disso, um teste de DNA revelou que amostras de sua urina, colhidas durante a competição, pertenciam a pessoas diferentes. Tal fato corroborou para que as suspeitas de que Rebeca tinha usado anabolizantes se confirmassem. Percebemos uma narrativa ressentida em que a perda, mais que simplesmente da atleta, é uma perda da nação.

A partir da apropriação das considerações de Kellner (2006) sobre a mídia e o esporte-espetáculo, em que "as celebridades são os ícones da cultura da mídia, os deuses e deusas da vida cotidiana” (KELLNER, 2006, p. 6), percebemos que esses discursos "ressentidos" situaram a atleta numa perda da condição de "deusa". Portanto, ela se tornou protagonista de um ser ídolo/herói de uma maneira cíclica e desconfiada. Isso se dá à medida que passou de "orgulho da nação" (com a conquista das medalhas), a "mau exemplo" (com o flagra nos exames).

Em outro texto também recai sobre as atletas do futebol feminino do Brasil, em especial a jogadora Marta, um discurso desconfiado. Não se contesta o talento da jogadora, mas, sobre ela incorre a responsabilidade de toda a equipe, de acordo com o que foi identificado em "O brilho das meninas: com grandes dribles de Marta, a seleção chega à final da Copa do Mundo feminina” (2007).

É enfatizado o mérito da seleção brasileira de futebol feminino, em especial da jogadora Marta Vieira, que, após marcar o quarto gol na vitória da seleção sobre as arqui-rivais americanas, foi aplaudida de pé. A atacante brasileira marcou dois gols na partida, um deles foi narrado com destreza comparável a grandes craques brasileiros como Pelé e Zico.

Seus dribles foram comparados a passos de samba (apelo identitário verificado) e deram a Marta o título de melhor jogadora do mundo pela Federação Internacional de Futebol (FIFA). Foi ressaltada a dificuldade do jogo contra a equipe alemã e exigiu-se: "Marta terá que caprichar ainda mais nos dribles"(JACOBSON, 2007, p. 129).

O título inédito, segundo o texto, transformaria o futebol feminino em paixão nacional (com investimentos e campeonatos, como o masculino). A conquista do 
título, como foi possível perceber - e, obviamente, todos os rituais míticos incutidos na cerimônia de comemoração -, influencia para que se alcance o status de herói e o nacionalismo seja, então, despertado.

Percebemos que o fator identitário, já constatado pelos autores Helal, Soares e Lovisolo (2001), no que se refere à modalidade futebol, também está presente no futebol feminino. No entanto, o texto analisado sugere uma identificação muito centralizada no talento e desempenho de uma atleta em particular.

A reportagem que apresenta o "craque" do salto triplo brasileiro - Gregório que, após o Grande Prêmio Brasil de Atletismo, entrou na história como um dos dez melhores atletas do mundo do salto triplo, reforça o ideal de nacionalismo. Afirmase que o atleta paranaense de 26 anos deseja aumentar sua coleção de títulos com a conquista de uma medalha olímpica. Em entrevista, o atleta reconheceu que ainda precisa melhorar.

Verificamos que o desejo de melhorar e conseguir a medalha olímpica passa por um processo de significação simbólica mediado pelo discurso midiático que tende a coletivizá-lo nacionalmente. No caminho inverso, qual a repercussão - e conseqüente representação social - que a, cada vez maior, expressividade de uma conquista lhe trará? Possivelmente a de ser visto como um herói nacional, um ídolo, um orgulho da nação, discursos (não coincidentemente) expressos, potencializados e "vendidos" por esta mesma mídia.

São questões suscitadas nessa dialética que trazem representações do atleta (como um ator social) ora cíclicas, paradoxais, reticentes. Tais representações ultrapassam o âmbito esportivo, pelo conjunto de valores sociais historicamente construídos que o "ser atleta" traz imbricado em si.

\section{Considerações finais}

A partir do entendimento de que o esporte de rendimento compõe o que Kellner (2006, p. 6) denomina de "campo do espetáculo", percebemos que a espetacularização do esporte moderno e a supervalorização dos resultados alcançados pelo atleta têm sugerido uma relação entre o protagonista do espetáculo esportivo e a figura do herói nas reportagens analisadas.

Nas atividades esportivas, o mito é a representação do herói. O mito esportivo possui características peculiares, são talentosos e carismáticos, e suas trajetórias de vida são narradas de forma a se tornarem paradigmas dos anseios sociais (HELAL; SOARES; LOVISOLO, 2001). As representações trazem, como inerentes a si, o simbólico. Segundo Pesavento (2003, p. 41), "dizem mais do que aquilo que mostram ou enunciam, carregam sentidos ocultos que, construídos social e historicamente, se internalizam no inconsciente coletivo e se apresentam como naturais".

A produção e veiculação de discursos da mídia sobre este campo do espetáculo sugerem a presença dessas representações também nas narrativas investigadas. Tais representações nos sinalizam que, advindo do cenário esportivo, o atleta como ator social simboliza, produz e reproduz o nacionalismo arraigado nas competições esportivas, assume a figura heróica, mítica, e traz consigo um modelo de comportamento que, por vezes, quando transgressor ou se subvertido, o torna vilão. 
Essas representações permeiam o imaginário social e influenciam questões como a identidade nacional (muito recorrente nas reportagens analisadas), o discurso moral em torno do esporte e do atleta mais especificamente. Contudo, corroboramos com Kellner (2006) sobre estas construções discursivas dominantes estarem passíveis de serem acatadas ou rejeitadas na formação da identidade.

Verificamos, portanto, que a repercussão do comportamento de um atleta extrapola a temática esportiva. Dessa forma, mobiliza debates sociológicos mais amplos que perpassam a cultura do ídolo esportivo, que é, ao mesmo tempo, fomentada e mediada pelas mídias. Tais debates incitam questões quanto à significação da relação do esporte de rendimento e formações discursivas a partir da criação de personagens míticos, heróicos e/ou transgressores, nos mais diversos aspectos sociais.

The media and the social representations of the sport: the athletes as models of behavior.

\begin{abstract}
The media has changed the communication processes and raised new communicative interactions between the social actors. These processes generate specific codes which produces perception, reception and social behavior effects. This study intends to identify how the athlete is represented as a social actor of sport in the media dicourse. Reports of Revista Veja - national circulation and high visibility in the brazilian printed media -, in the sport section from January of 2007 to January of 2008 were analyzed. It was verified the mythical figure of the athlete as a social actor of sport, and his representations as a behavior model.
\end{abstract}

Keywords: Printed Media - Athlete - Content Analysis.

Los medios de comunicación y las representaciones sociales del deporte: los atletas como modelos de comportamiento.

\title{
Resumen \\ Los medios han transformado los procesos de comunicación y suscitado nuevas interacciones comu- nicativas entre los actores sociales. Tales procesos generan códigos específicos que producen efectos de percepción, recepción y comportamientos sociales. Este estudio buscó identificar de qué forma el atleta se constituye como actor social del deporte en el discurso mediático. Fueron analizados los reportajes de la Revista Veja (de circulación nacional y gran visibilidad en los medios de prensa brasileña), presentes en la sección de deportes de enero de 2007 a enero de 2008. Se verificó la figura mítica del atleta como actor social del deporte, así como sus representaciones como modelo de comportamiento.
}

Palabras claves: Medios Gráficos - Atleta - Análisis de Contenido.

\section{Referências}

BORTOLOTI, M. Phelps brasileiro: Recorde mundial faz de Thiago Pereira a grande promessa da natação para Pequim. Revista Veja, São Paulo, 2036 ed., p.98-99, 28 nov. 2007 a.

. Contra Hermanos e juvenis é fácil: o Brasil nunca teve tantos ouros. Mas, poucos atletas podem repetir o feito nas Olimpíadas. Revista Veja, São Paulo, 2019 ed., p.88-89, 01 ago. 2007b.

BRASIL, S. Pisou na bola: ao arquivar ação de jogador, juiz afirma que gays não têm espaço no viril futebol. Revista Veja, São Paulo, 2021 ed., p.100, 15 ago. 2007. 
BRIGGS, A.; BURKE, P. Uma história social da mídia: de Gutenberg à internet. [Tradução Maria Carmelita Pádua Dias]. Rio de Janeiro: Jorge Zahar, 2004.

FAVARO, T. Craque de exportação: desconhecidos no Brasil, craques em início de carreira fazem sucesso no exterior. Revista Veja, São Paulo, 2017ed., p.76, 18 jul. 2007.

FISCHER, R. M. B. Problematizações sobre o exercício de ver: mídia e pesquisa em Educação. Revista Brasileira de Educação, São Paulo, n. 20, p. 83-94, 2002.

HELAL, R.; SOARES, A.J.; LOVISOLO, H. A invenção do país do futebol: mídia, raça e idolatria. Rio de Janeiro, Mauad, 2001.

JACOBSON, J. O brilho das meninas: com grandes dribles de Marta, a seleção chega à final da Copa do Mundo feminina. Revista Veja, São Paulo, 2028 ed., p.129, 03 out. 2007.

KELLNER, D. A cultura da mídia e o triunfo do espetáculo. [Tradução: Rosemary Duarte], Líbero, ano VI, v. 6, n. 11, 2006.

LIMA, R. de A. Fraude na piscina: exame antidoping flagra Rebeca Gusmão, vencedora de duas medalhas de ouro no Pan. Revista Veja, São Paulo, 2034 ed., p.120, 14 nov. 2007.

MINAYO, M. C. de S.; NETO, O. C.; DESLANDES, S. F. (Orgs.). Pesquisa social: teoria, método e criatividade. 22 ed. Rio de Janeiro: Vozes, 2003.

PESAVENTO, S. J. História e Histórica Cultural. Belo Horizonte: Autêntica, 2003.

PIRES, G. de L. A Educação Física e o discurso midiático: abordagem crítico-emancipatória em pesquisa-ação no ensino de graduação. 2000. 229 f. Tese (Doutorado em Ciência do Movimento Humano) - Faculdade de Educação Física, Universidade Estadual de Campinas, Campinas, 2001.

RUBIO, K. O trabalho do atleta e a produção do espetáculo esportivo. Revista Electrónica de Geografía y Ciencias Sociales. Universidad de Barcelona, v. VI, n. 119 (95), 1 ago. 2002.

SALVADOR, A. jovem de grande valor: em apenas um ano Breno passou de Júnior a craque do São Paulo, e agora, vai para o Bayern de Munique. Revista Veja, São Paulo, 2039 ed., p.126, 19 dez. 2007.

. "Quero ganhar tudo duas vezes": talentoso e com fama de bom moço, Kaká termina uma temporada de sucesso no Milan e fala sobre o futuro e o plano de se tornar pastor evangélico. Revista Veja, São Paulo, 2039 ed., p. 128, 19 dez. 2007.

A baixinha vence as gigantes: tenista número 1 do mundo Justine Henin precisou superar não somente a altura das rivais, mas também a asma e um passado sofrido. Revista Veja, São Paulo, 2035 ed., p.126-127, 21 nov. 2007.

SOARES, R. Próximo do limite: mesmo sem as principais estrelas, o Pan do Brasil reunirá máquinas humanas em busca de novos recordes. Revista Veja, São Paulo, 2012 ed., p.74-76, 13 jun. 2007. 
TEIXEIRA, D. Brasileira de ouro: a paranaense Angela Park torna-se a atleta nacional mais bem-sucedida no golfe internacional. Revista Veja, São Paulo, 2016 ed., p. 98-99, 11 jul. 2007.

THOMPSON, John B. Ideologia e cultura moderna: teoria social crítica na era dos meios de comunicação de massa. Petrópolis: Vozes, 1995.

Recebido em: 28/10/2009

Revisado em: 02/11/2009

Aprovado em: 19/11/2009

Endereço para correspondência

Doiara Silva dos Santos

Universidade Federal do Espirito Santo

Faculdade de Educação Física

Avenida Fernando Ferrari, 514 Campus de Goiabeiras,

CEP.: 29.075-910

Vitória - Espirito Santo - Brasil

E-mail:doiarasantos@yahoo.com.br 